\title{
Clinical Effects of Topiroxostat on Renal and Endothelial Function in A Patient with Chronic Kidney Disease and Hyperuricemic Arteriolopathy: A Case Report
}

\author{
Atsushi Tanaka $^{1} \cdot$ Tsukasa Nakamura $^{2} \cdot$ Eiichi Sato $^{2} \cdot$ Koichi Node $^{1}$
}

Published online: 10 January 2017

(C) The Author(s) 2017. This article is published with open access at Springerlink.com

\begin{abstract}
Hyperuricemia is associated with the progression of chronic kidney disease (CKD) and cardiovascular diseases. Topiroxostat, a selective xanthine oxidase inhibitor, effectively reduces serum uric acid (UA) levels and urinary albumin excretion (UAE) in CKD patients. A 50-year-old Japanese man was referred to our hospital due to albuminuria and hyperuricemia, and renal biopsy showed a typical hyperuricemic arteriolopathy. Treatment with topiroxostat decreased serum UA levels $(9.2 \mathrm{mg} / \mathrm{dL}$ at baseline to $6.4 \mathrm{mg} / \mathrm{dL}$ after 6 months), UAE (388 to $88 \mathrm{mg} / \mathrm{g} . \mathrm{cr}$ ), and urinary level of liver-type fatty acidbinding protein (28.8 to $19.8 \mu \mathrm{g} / \mathrm{g} . \mathrm{cr}$ ). Interestingly, topiroxostat treatment was associated with a trend towards improved flow-mediated dilation (5.4 to 5.8\%). These results suggested that topiroxostat in CKD patients with hyperuricemia is potentially effective, not only for ameliorating renal damages but also for improving endothelial function beyond its UA-lowering action.
\end{abstract}

Koichi Node

node@cc.saga-u.ac.jp

1 Department of Cardiovascular Medicine, Saga University, 5-1-1 Nabeshima, Saga 849-8501, Japan

2 Division of Nephrology, Department of Internal Medicine, Shinmatsudo Central General Hospital, Matsudo, Japan

\section{Key Points}

In the present case report, topiroxostat treatment in hyperuricemic patients with renal arteriolopathy reduced renal damage and increased flow-mediated dilation value.

Further studies are needed to assess the protective effects of topiroxostat treatment on renal and endothelial function in hyperuricemic patients.

\section{Introduction}

Elevated levels of serum uric acid (UA) are closely associated with an increased risk for mortality in patients with chronic kidney disease (CKD) [1]. Hyperuricemia has been shown to be a significant and independent risk factor for the development of kidney disease and albuminuria in the general Japanese population [2], and an animal study suggested that hyperuricemia may cause progression of hypertension and CKD by inducing pre-glomerular arteriolar damage, characterized by hyalinosis, wall thickening, and an increased number of smooth muscle cells [3]. Injuries to pre-glomerular arterioles cause glomerular hypertension and ischemia, which are universal risk factors for the progression of renal damage [3, 4]. A study of renal biopsies collected from hyperuricemic patients suggested that high levels of serum UA may be associated with the development of renal arteriolopathy and may play a pivotal role in the progression of renal injuries [5].

There are some evidence that UA-lowering treatment is effective for delaying the progression of CKD associated 
with hyperuricemia [6]. In studies of $\mathrm{db} / \mathrm{db}$ mice, topiroxostat, a selective xanthine oxidase (XO) inhibitor, caused a dose-dependent decrease in both urinary albumin excretion (UAE) and plasma XO activity; however, in contrast, another XO inhibitor, febuxostat, showed no such effect [7]. In addition, topiroxostat $160 \mathrm{mg}$ was reported to effectively and safely decrease serum UA levels and UAE in hyperuricemic patients with stage III CKD [8]. Taken together, these results suggest topiroxostat may have a renal protective effect over and above its UA-lowering action. In the present report, we describe a patient with renal biopsy-proven hyperuricemic arteriolopathy in whom topiroxostat reduced not only UAE but also urinary livertype fatty acid-binding protein (L-FABP), a marker of tubulointerstitial injury, and flow-mediated dilation (FMD), a marker of endothelial dysfunction.

\section{Case Presentation}

A 50-year-old Japanese male was referred to our hospital due to albuminuria and hyperuricemia. At 40 years of age, the patient had been diagnosed with hyperuricemia $(8.4 \mathrm{mg} / \mathrm{dL})$ in another clinic but did not receive follow-up treatment at that time. Then, at 50 years of age, he visited the same clinic and was again diagnosed with hyperuricemia $(9.0 \mathrm{mg} / \mathrm{dl})$ and high UAE $(390 \mathrm{mg} / \mathrm{g} . \mathrm{cr})$, leading to admission to our hospital for a detailed examination of CKD. He had no history of smoking or major diseases, excluding hyperuricemia, and no family history of renal diseases. Clinical examination and laboratory tests at admission showed the following characteristics: height $170 \mathrm{~cm}$, weight $68 \mathrm{~kg}$, blood pressure 130/82 $\mathrm{mmHg}$, heart rate 70 beats $/ \mathrm{min}$, serum UA $9.2 \mathrm{mg} / \mathrm{dL}$, UAE $388.6 \mathrm{mg} /$ g.cr, urinary L-FABP $28.8 \mu \mathrm{g} / \mathrm{g} . \mathrm{cr}$ (normal range $<8.4 \mu \mathrm{g}$ / g.cr), serum creatinine $1.32 \mathrm{mg} / \mathrm{dL}$, estimated glomerular filtration ratio $46.6 \mathrm{~mL} / \mathrm{min} / 1.73 \mathrm{~m}^{2}$, no hematuria, normal proteinemia (serum total protein $7.0 \mathrm{~g} / \mathrm{dL}$, serum albumin $4.2 \mathrm{~g} / \mathrm{dL}$ ), normoglycemia (fasting blood sugar $96 \mathrm{mg} / \mathrm{dL}$, $\mathrm{HbA} 1 \mathrm{c} 5.6 \%$ ), and normal lipid profile (low-density lipoprotein cholesterol $126 \mathrm{mg} / \mathrm{dL}$, triglycerides $96 \mathrm{mg} / \mathrm{dL}$, high-density lipoprotein cholesterol $66 \mathrm{mg} / \mathrm{dL}$ ). Plasma serology was negative for antinuclear antibody, antiglomerular basement membrane antibody, myeloperoxidase antineutrophil cytoplasmic antibody (ANCA), proteinase 3-ANCA, hepatitis C antibody, and hepatic B antigen. Serum complement and immunoglobulin levels were within normal limits, and the FMD value was $5.4 \%$ (normal range $>6.0 \%$ ).

A renal biopsy was performed on day 3 after admission. Renal histopathology showed renal arteriolar hyalinosis and arteriolar wall thickening, tubular atrophy, and interstitial fibrosis, but only minor changes in the glomeruli
(Fig. 1). These findings were compatible with renal arteriolopathy related to hyperuricemia [5]. In addition, immunohistochemistry for deposition of immunoglobulin $\mathrm{G}(\mathrm{IgG}), \operatorname{IgM}, \operatorname{Ig} \mathrm{A}, \mathrm{C} 3$, and $\mathrm{C} 1 \mathrm{q}$ were all negative. The patient was therefore diagnosed with hyperuricemic arteriolopathy. Because of its potential renal protective effect described earlier, topiroxostat treatment $(160 \mathrm{mg} /$ day $)$ was initiated on day 7 . The serial changes in laboratory data pre- and post-topiroxostat treatment are shown in Table 1 . The patient's serum UA level decreased from 9.2 to $7.4 \mathrm{mg} / \mathrm{dL}$ after 3 months and $6.4 \mathrm{mg} / \mathrm{dL}$ after 6 months, while UAE decreased from 388.6 to $288.2 \mathrm{mg} / \mathrm{g}$.cr after 3 months and $88.4 \mathrm{mg} / \mathrm{g} . c r$ after 6 months. The urinary L-FABP level also decreased from 28.8 to $24.2 \mu \mathrm{g} / \mathrm{g}$.cr after 3 months and $19.8 \mu \mathrm{g} / \mathrm{g}$.cr after 6 months. In addition, FMD increased slightly from 5.4 to $5.6 \%$ after 3 months and $5.8 \%$ after 6 months. Other parameters, including blood pressure, renal function, and lipid profile, showed only minor changes during the 6-month treatment period. No adverse drug reaction was observed.

\section{Discussion}

The present case of hyperuricemia and biopsy-proven renal arteriolar injury is the first to demonstrate that treatment with topiroxostat has the ability to decrease serum UA, UAE, and urinary L-FABP levels, and increase FMD value.

Hyperuricemia is strongly associated with a wide range of complications, such as hypertension, metabolic syndrome, cardiovascular disease, and CKD [9-13]. UAlowering therapy is therefore important to prevent or delay the progression of these diseases. Previous experimental animal studies demonstrated that hyperuricemia could cause progression of CKD by inducing pre-glomerular arteriolar damages, characterized by hyalinosis and wall thickening [3, 4]. Kohagura et al. [5] reported an association between UA levels in hyperuricemic CKD patients and parameters of renal arteriolopathy, such as hyalinosis and wall thickening. It is suggested that the association between hyperuricemia and renal arteriolar damages could potentially induce glomerular hypertension and resultant progression of CKD [5, 14]. It would therefore be anticipated that UA-lowering therapy should slow the progression of CKD and improve renal outcomes in patients with hyperuricemia and CKD [15]. Topiroxostat is a non-purine selective XO inhibitor approved in Japan as a UA-lowering agent [16]. High doses of topiroxostat $(160 \mathrm{mg} /$ day) were shown to reduce UAE and serum UA levels compared with placebo in patients with hyperuricemia and stage III CKD with or without gout [8]. It was also recently reported that urinary excretion of L-FABP was significantly lower in an 

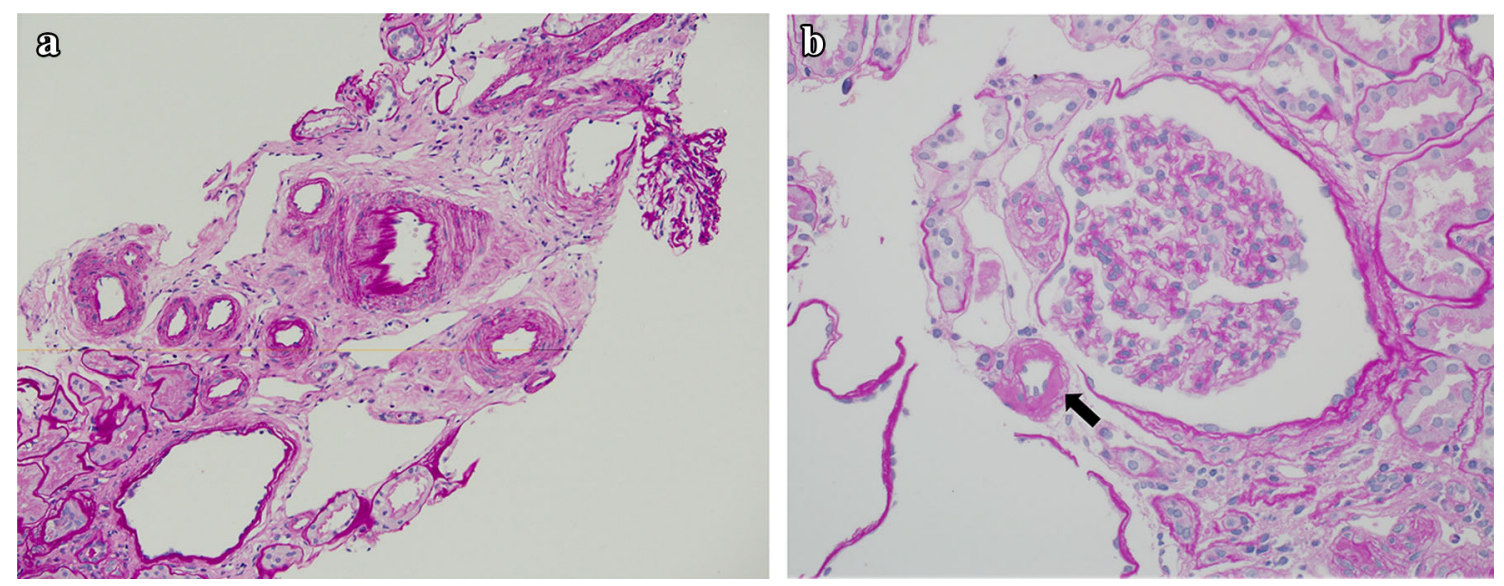

Fig. 1 Histopathology of kidney specimens. a Vascular wall thickening and interstitial fibrosis are prominent features in the sections (PAS staining $\times 200$ ). b Hyalinosis in the afferent arteriole (arrow) (PAS staining $\times 400$ ). PAS periodic acid-Schiff

Table 1 Serial changes in laboratory and clinical indices over the 6-month treatment period

\begin{tabular}{llll}
\hline Variables & Pre-treatment & After 3 months & After 6 months \\
\hline Systolic/diastolic blood pressure, mmHg & $130 / 82$ & $128 / 80$ & $128 / 80$ \\
Low-density lipoprotein cholesterol, mg/dL & 126 & 124 & 122 \\
High-density lipoprotein cholesterol, mg/dL & 66 & 68 & 66 \\
Triglyceride, mg/dL & 98 & 100 & 100 \\
Serum creatinine, mg/dL & 1.32 & 1.30 & 1.28 \\
Blood urea nitrogen, mg/dL & 22 & 22 & 20 \\
Uric acid, mg/dL & 9.2 & 7.4 & 6.4 \\
Urinary albumin excretion, mg/g.cr & 388.6 & 288.2 & 88.4 \\
Liver-type fatty acid-binding protein, $\mu \mathrm{g} / \mathrm{g} . \mathrm{cr}$ & 28.8 & 24.2 & 19.8 \\
Flow-mediated dilation, $\%$ & 5.4 & 5.6 & 5.8 \\
\hline
\end{tabular}

animal model of adenine-induced renal injury treated with topiroxostat compared with animals treated with febuxostat [17]. Urinary L-FABP is approved as a clinical biomarker of tubular damage and may be a useful prognostic biomarker of progression to end-stage renal disease and the onset of cardiovascular disease in patients with CKD [18]. On the basis of these results, in the present case we decided to administer topiroxostat $160 \mathrm{mg} /$ day, but not febuxostat.

A previous study provided an interesting insight in that an excess level of UA may have a direct effect on the cells that determine the structure of vessels [5]. In this regard, UA has been shown to promote proliferation of vascular smooth muscle cells and reduce nitric oxide, resulting in endothelial dysfunction [19]. On the other hand, Chen et al. [20] reported an interrelationship between multiple markers and pathways, leading to impaired endothelial function in patients with CKD. Given these relationships, there seems to be a pathological triangle between hyperuricemia, CKD, and endothelial dysfunction. However, some recent studies have reported conflicting results with decreased serum UA levels induced by allopurinol, a conventional $\mathrm{XO}$ inhibitor, increasing FMD in patients with stage II-IV
CKD and plasma UA levels $>5.5 \mathrm{mg} / \mathrm{dL}$ [21]. In contrast, another study showed that allopurinol did not improve endothelial function in asymptomatic hyperuricemic patients with stage III CKD [22]. Therefore, it remains controversial whether UA-lowering therapy improves endothelial function in hyperuricemic patients with CKD. Moreover, the precise mechanisms by which XO inhibitors modulate endothelial function have yet to be elucidated. The present case of a patient treated with topiroxostat was the first to show an increase in the FMD value after 6 months of treatment; however, no data regarding whether there is a dose-dependent effect on endothelial function and whether XO inhibitors exert as a class effect are currently available. Recent randomized trials on post cardiac surgery hyperuricemic patients with or without CKD showed that febuxostat provided superior anti-inflammatory and renoprotective effects than allopurinol [23, 24]. A randomized trial to assess the effect of febuxostat on atherosclerosis and vascular function over 24 months is currently ongoing in Japan [25]. Furthermore, the ETUDE study group in Japan has also started a randomized study to clarify the renoprotective effect of topiroxostat and evaluate the safety 
of its serum UA level-lowering effect in patients with diabetic nephropathy and hyperuricemia [26]. Thus, increasing attention is being given to the protective effects of newer XO inhibitors on renal and cardiovascular systems beyond their UA-lowering action.

\section{Conclusions}

We report a case of a patient with CKD and biopsy-proven hyperuricemic-associated arteriolopathy in whom topiroxostat treatment was effective in reducing serum UA, UAE, and urinary L-FABP levels, and in increasing FMD value. This finding indicates that large-scale and long-term randomized trials are warranted to test the protective effects of topiroxostat treatment on renal and endothelial function in hyperuricemic patients.

Acknowledgements The authors wish to thank Professor Yoshihiko Ueda, Department of Pathology, Koshigaya Hospital, Dokkyo University School of Medicine, Saitama, Japan, for technical help with the preparation and examination of the renal histology.

\section{Compliance with Ethical Standards}

Funding This case report was not supported by any funding bodies.

Conflicts of interest Koichi Node has received honoraria from Boehringer Ingelheim, Daiichi Sankyo, Novartis, Astellas, Kowa, Bayer, Merck, Takeda, Pfizer, Mitsubishi Tanabe, TEIJIN, Sanofi, Kyowa Hakko Kirin, AstraZeneca; and research Grants from Astellas, AstraZeneca, Otsuka, Kyowa Hakko Kirin, Sanofi, Sanwa Kagaku Kenkyusho, Daiichi Sankyo, Sumitomo Dainippon, Takeda, Mitsubishi Tanabe, TEIJIN, Boehringer Ingelheim, Novartis, Pfizer, Bristol-Myers Squibb, and Merck. Atsushi Tanaka, Tsukasa Nakamura and Eiichi Sato declare no conflicts of interest.

Open Access This article is distributed under the terms of the Creative Commons Attribution-NonCommercial 4.0 International License (http://creativecommons.org/licenses/by-nc/4.0/), which permits any noncommercial use, distribution, and reproduction in any medium, provided you give appropriate credit to the original author(s) and the source, provide a link to the Creative Commons license, and indicate if changes were made.

\section{References}

1. Xia X, Luo Q, Li B, Lin Z, Yu X, Husng F. Serum uric acid and mortality in chronic kidney disease: a systemic review and metaanalysis. Metabolism. 2016;65:1326-41.

2. Takae K, Nagata M, Hata J, Mukai N, Hirakawa Y, Yoshida D, et al. Serum uric acid as a risk factor for chronic kidney disease in a Japanese community: the Hisayama Study. Circ J. 2016;80:1857-62.

3. Kang DH, Nakagawa T, Feng L, Watanabe S, Han L, Mazza M, et al. A role for uric acid in the progression of renal disease. J Am Soc Nephrol. 2002;13:2888-97.

4. Mazzali M, Kanellis J, Han L, Feng L, Xia YY, Chen Q, et al. Hyperuricemia induces a primary renal arteriolopathy in rats by a blood pressure-independent mechanism. Am J Physiol Renal Physiol. 2002;282:F991-7.

5. Kohagura K, Koichi M, Miyagi T, Kinjo T, Maehara Y, Nagahama $\mathrm{K}$, et al. An association between uric acid levels and renal arteriopathy in chronic kidney disease: a biopsy-based study. Hypertens Res. 2013;36:43-9.

6. Siu YP, Leung KT, Tong MK, Kwan TH. Use of allopurinol in slowing the progression of renal disease through its ability to lower serum uric acid level. Am J Kidney Dis. 2006;47:51-9.

7. Nakamura T, Murase T, Nampei M, Morimoto N, Ashizawa N, Iwanaga $\mathrm{T}$, et al. Effects of topiroxostat and febuxostat on urinary albumin excretion and plasma xanthine oxidoreductase activity in $\mathrm{db} / \mathrm{db}$ mice. Eur J Pharmacol. 2016;780:224-31.

8. Hosoya T, Ohno I, Nomura S, Hisatome I, Uchida S, Fujimori S, et al. Effects of topiroxostat on the serum urate levels and urinary albumin excretion in hyperuricemic stage 3 chronic kidney disease patients with or without gout. Clin Exp Nephrol. 2014; 18:876-84.

9. Choi HK, Ford ES, Li C, Curhan G. Prevalence of the metabolic syndrome in patients with gout: the Third National Health and Nutrition Examination Survey. Arthritis Rheum. 2007;57:109-15.

10. Wang J, Qin T, Chen J, Li Y, Wang L, Huang H, et al. Hyperuricemia and risk of incident hypertension: a systematic review and meta-analysis of observational studies. PLoS One. 2014;9:e114259.

11. Borghi C, Rosei EA, Bardin T, Dawson J, Dominiczak A, Kielstein JT, et al. Serum uric acid and the risk of cardiovascular and renal disease. J Hypertens. 2015;33:1729-41.

12. Li L, Yang C, Zhao Y, Zeng X, Liu F, Fu P. Is hyperuricemia an independent risk factor for new-onset chronic kidney disease? A systematic review and meta-analysis based on observational cohort studies. BMC Nephrol. 2014;15:122.

13. Uchida S, Chang WX, Ota T, Tamura Y, Shiraishi T, Kumagai T, et al. Targeting uric acid and the inhibition of progression to endstage renal disease: a propensity score analysis. PLoS One. 2015;10:e145506.

14. Sánchez-Lozada LG, Tapia E, Avila-Casado C, Soto V, Franco M, Santamaría J, et al. Mild hyperuricemia induces glomerular hypertension in normal rats. Am J Physiol Renal Physiol. 2002;283:F1105-10.

15. Bose B, Badve SV, Hiremath SS, Boudville N, Brown FG, Cass A, et al. Effects of uric acid-lowering therapy on renal outcomes: a systematic review and meta-analysis. Nephrol Dial Transplant. 2014;29:406-13.

16. Matsumoto K, Okamoto K, Ashizawa N, Nishino T. FYX-051: a novel and potent hybrid-type inhibitor of xanthine oxidoreductase. J Pharmacol Exp Ther. 2011;336:95-103.

17. Kamijo-Ikemori A, Sugaya T, Hibi C, Nakamura T, Murase T, Oikawa $\mathrm{T}$, et al. Renoprotective effect of the xanthine oxidoreductase inhibitor topiroxostat on adenine-induced renal injury. Am J Physiol Renal Physiol. 2016;310:F1366-76.

18. Matsui K, Kamijo-Ikemori A, Imai N, Sugaya T, Yasuda T, Tatsunami $\mathrm{S}$, et al. Clinical significance of urinary liver-type fatty acid-binding protein as a predictor of ESRD and CVD in patients with CKD. Clin Exp Nephrol. 2016;20:195-203.

19. Khosla UM, Zharikov S, Finch JL, Nakagawa T, Roncal $\mathrm{C}, \mathrm{Mu}$ $\mathrm{W}$, et al. Hyperuricemia induces endothelial dysfunction. Kidney Int. 2005;67:1739-42.

20. Chen J, Hamm LL, Mohler ER, Hudaihed A, Arora R, Chen CS, et al. Interrelationship of multiple endothelial dysfunction biomarkers with chronic kidney disease. PLoS One. 2015;10:e132047.

21. Bayram D, Tuğrul Sezer M, İnal S, Altuntaş A, Kıdır V, Orhan H. The effects of allopurinol on metabolic acidosis and endothelial 
functions in chronic kidney disease patients. Clin Exp Nephrol. 2015;19:443-9.

22. Jalal DI, Decker E, Prrenoud L, Nowak KL, Bispham N, Mehta $\mathrm{T}$, et al. Vascular function and uric acid-lowering in stage $3 \mathrm{CKD}$. J Am Soc Nephrol (Epub 12 Sep 2016). pii: ASN.2016050521.

23. Sezai A, Soma M, Nakata K, Hata M, Yoshitake I, Wakui S, et al. Comparison of febuxostat and allopurinol for hyperuricemia in cardiac surgery patients (NU-FLASH Trial). Circ J. 2013;77:2043-9.

24. Sezai A, Soma M, Nakata K, Osaka S, Ishii Y, Yaoita H, et al. Comparison of febuxostat and allopurinol for hyperuricemia in cardiac surgery patients with chronic kidney disease (NU-FLASH trial for CKD). J Cardiol. 2015;66:298-303.
25. Oyama J, Tanaka A, Sato Y, Tomiyama H, Sata M, Ishizu T, et al. PRIZE Study Investigators. Rationale and design of a multicenter randomized study for evaluating vascular function under uric acid control using the xanthine oxidase inhibitor, febuxostat: the PRIZE study. Cardiovasc Diabetol. 2016;15:87.

26. Kato S, Ando M, Mizukoshi T, Nagata T, Katsuno T, Kosugi T, et al. Randomized control trial for the assessment of the antialbuminuric effects of topiroxostat in hyperuricemic patients with diabetic nephropathy (the ETUDE study). Nagoya J Med Sci. 2016;78:135-42. 